\title{
Acupuncture for Paclitaxel-Induced Peripheral Neuropathy: A Review of Clinical and Basic Studies
}

This article was published in the following Dove Press journal:

Journal of Pain Research

\author{
Yu-Xue Zhao (iD) \\ Xiao-Chun Yu' \\ Jun-Hong Gao' \\ Ming-Jiang $\mathrm{Yao}^{2,3}$ \\ Bing Zhu'
}

\begin{abstract}
'Institute of Acupuncture and Moxibustion, China Academy of Chinese Medical Sciences, Beijing, 100700 , People's Republic of China; ${ }^{2}$ Institute of Basic Medical Sciences, Xiyuan Hospital of China Academy of Chinese Medical Sciences, Beijing, I0009I, People's Republic of China; ${ }^{3}$ Key Laboratory of Pharmacology of Chinese Materia Medica, Beijing, I0009I, People's Republic of China
\end{abstract}

\begin{abstract}
Paclitaxel-induced peripheral neuropathy (PIPN) is a common and intractable side effect of the conventional chemotherapeutic agent paclitaxel. Acupuncture has been reported as an effective alternative therapy in treatment of PIPN in both basic studies and clinical trials. However, there is a lack of comprehensive surveys to summarize the action of acupuncture in management of PIPN. In this review, we briefly demonstrate the basic pathology of PIPN, which includes the activation of ion channels, mitochondrial dysfunction, disruption of axonal transport and also neuro-inflammatory involvement. Meanwhile, we review both the clinical and basic studies as an emphasis to give a general overview of the therapeutic effect of acupuncture against PIPN. Finally, we summarize the current known mechanisms underlying the action of acupuncture against PIPN mainly at peripheral and spinal levels, which include various neurotransmitters, multiple receptors, different types of enzymes and molecules. In conclusion, acupuncture could be considered as a potential alternative therapy in treatment of PIPN, and further clinical and experimental studies are called for in the future.
\end{abstract}

Keywords: paclitaxel, peripheral neuropathy, acupuncture

\section{Introduction}

Chemotherapy-induced peripheral neuropathy (CIPN) is a common and severe adverse effect of modern chemotherapy and affects long-term quality of life. ${ }^{1,2}$ Approximately up to $40 \%$ of cancer patients treated with neurotoxic chemotherapeutic agents develop CIPN, which can be a significant disability and a common cause of dose reductions and/or early discontinuation of chemotherapy. ${ }^{3,4}$ The most frequent substances causing CIPN include the commonly used taxanes (paclitaxel, docetaxel), vinca alkaloids (vincristine, vinblastine), platinum compounds (cisplatin, oxaliplatin, carboplatin), as well as the rarely used thalidomide and bortezomib. ${ }^{3-5}$ Paclitaxel, the first taxane in clinical practice, is used actively against a broad spectrum of cancers (including breast cancer, ovarian cancer, cervical cancer, lung cancer and pancreatic cancer) that are generally considered to be intractable to conventional chemotherapy. Up to $80 \%$ of patients develop paclitaxel-induced peripheral neuropathy (PIPN). ${ }^{6,7}$ Unfortunately, the current existing therapeutic strategies have been shown to be ineffective or unsatisfactory to prevent or minimize PIPN to date. ${ }^{8}$ Therefore, it is highly required to explore and develop potential effective approaches during paclitaxel chemotherapy to ameliorate PIPN.

Acupuncture, with a history over 3000 years, is a traditional therapy in which specially-made acupuncture needles are inserted into specific "acupuncture points" (acupoints, namely therapeutic points in the human body) to treat various
Correspondence: Yu-Xue Zhao; Bing Zhu Institute of Acupuncture and Moxibustion, China Academy of Chinese Medical Sciences, No. 16 Dong-zhi-men-nei South Street, Dongcheng District, Beijing, 100700 , People's Republic of China

Tel +86-10-64089363

Email claricezhao@live.cn; zhubing@mail. cintcm.ac.cn
Journal of Pain Research 2021:14 993-1005 
disorders. ${ }^{9,10}$ Acupuncture has been proven to be an effective analgesic intervention in management of diverse types of pain, such as inflammatory pain, visceral pain, cancer pain, and neuropathic pain, including chemotherapyinduced neuropathic pain. ${ }^{11-15}$ A series of clinical studies have reported the beneficial effect of acupuncture strategy on improving the symptoms of CIPN that is induced by oxaliplatin, thalidomide, bortezomib and taxane. ${ }^{16-20}$ Besides, animal studies have been conducted to investigate the mechanism underpinning the therapeutic efficacies of acupuncture in CIPN as well. ${ }^{21-25}$ As a first-line chemotherapeutic agent, taxane (particularly paclitaxel) leads to common and typical CIPN, which is introduced and investigated in both clinical and basic studies. So far, there is still a lack of comprehensive surveys to summarize the action of acupuncture in management of PIPN. Herein, the scope of the current review is to present an overall idea on the therapeutic potential of acupuncture against PIPN along with the related underlying mechanism based upon the existing clinical and experimental evidence, so as to better understand the analgesic efficacy of this kind of traditional medical therapy and to objectively evaluate its application prospect in clinical practice.

In this review, we first briefly summarize the basic pathology of PIPN, with a particular emphasis on the leading pathogenic factors; and then we synthesize both the clinical and basic studies to give an overview of the therapeutic effect of acupuncture on alleviating PIPN, together with the potential mechanisms involved in order to interpret the analgesic action of acupuncture; finally, we present the limitations of our current review, and discuss the future perspectives including clinical application and basic investigation of acupuncture in the treatment of PIPN.

\section{Literature Search Strategy}

The following databases were searched from January 2010 to December 2020: PubMed, Web of Science, CNKI and Wan-Fang Database. The search key words related to "acupuncture", "electroacupuncture", "electro-acupuncture", "transcutaneous electrical stimulation", "paclitaxel”, "taxane", "pain", "neuropathy", "animal studies", and "clinical trials". Literature inclusion criteria were as follows: 1 . Clinical studies and experimental studies on neuropathy/pain after paclitaxel/taxane administration; and 2. Treatment using acupuncture therapy (including manual acupuncture, electroacupuncture, point injection, etc.).

\section{Pathology of PIPN}

The underlying mechanism leading to the occurrence and development of PIPN is complex, with multiple pathological factors, and has not been fully elucidated. In general, paclitaxel causes damage to distal nerve fibers and lead to painful peripheral neuropathy mainly by affecting ion channels, mitochondrial function, and axonal transport and also by interfering with the neuro-immune response (Figure 1).

\section{Ion Channels}

PIPN is related to abnormal sensitization of peripheral sensory neurons, which could be induced by initial activation of ion channels after paclitaxel treatment. ${ }^{26,27}$ Paclitaxel administration has been reported to activate both voltage-gated and ligand-gated ion channels, which was discovered by application of the corresponding selective ion channel antagonists in rodent models of PIPN. It is well documented that lack of intracellular cation homeostasis is a major cause in the development of PIPN. ${ }^{28-30}$ Prominent down-regulation of potassium channels in dorsal root ganglion (DRG) that potentiated the increased spontaneous activity of primary sensory neurons has been shown with paclitaxel chemotherapy. ${ }^{28}$ Besides, altered sodium channel expression in sensory fibers conduces to neuropathic pain, and administration of the sodium channels blocker tetrodotoxin inhibited paclitaxelinduced hyperalgesia in mice, indicating sodium channel contributes to PIPN. ${ }^{29}$ An almost complete reversal of paclitaxel-induced mechanical allodynia/hyperalgesia was elicited by a selective calcium channels inhibitor ethosuximide, suggesting the involvement of calcium channels in PIPN. ${ }^{30}$ Ligand-gated ion channels, including transient receptor potential (TRP) channels (TRPA1, TRPM8, TRPV1, and TRPV4), ${ }^{31-34}$ Toll-like receptors (TLRs) channels (TLR4 and TLR9), ${ }^{27,35}$ and purine receptors channels (P2X7 and adenosine A1), ${ }^{36,37}$ have been found to contribute to PIPN in rodents. Paclitaxel-induced mechanical allodynia/hyperalgesia were attenuated by selective blockage of the TRPs, TLRs, and purine receptors.

\section{Mitochondrial Dysfunction}

Mitochondria are double-membrane-bound intracellular organelles that produce adenosine triphosphate (ATP) mainly through oxidative phosphorylation to provide cellular energy. Neuronal cells require high energy for neuronal activities and are susceptible to be disrupted in 

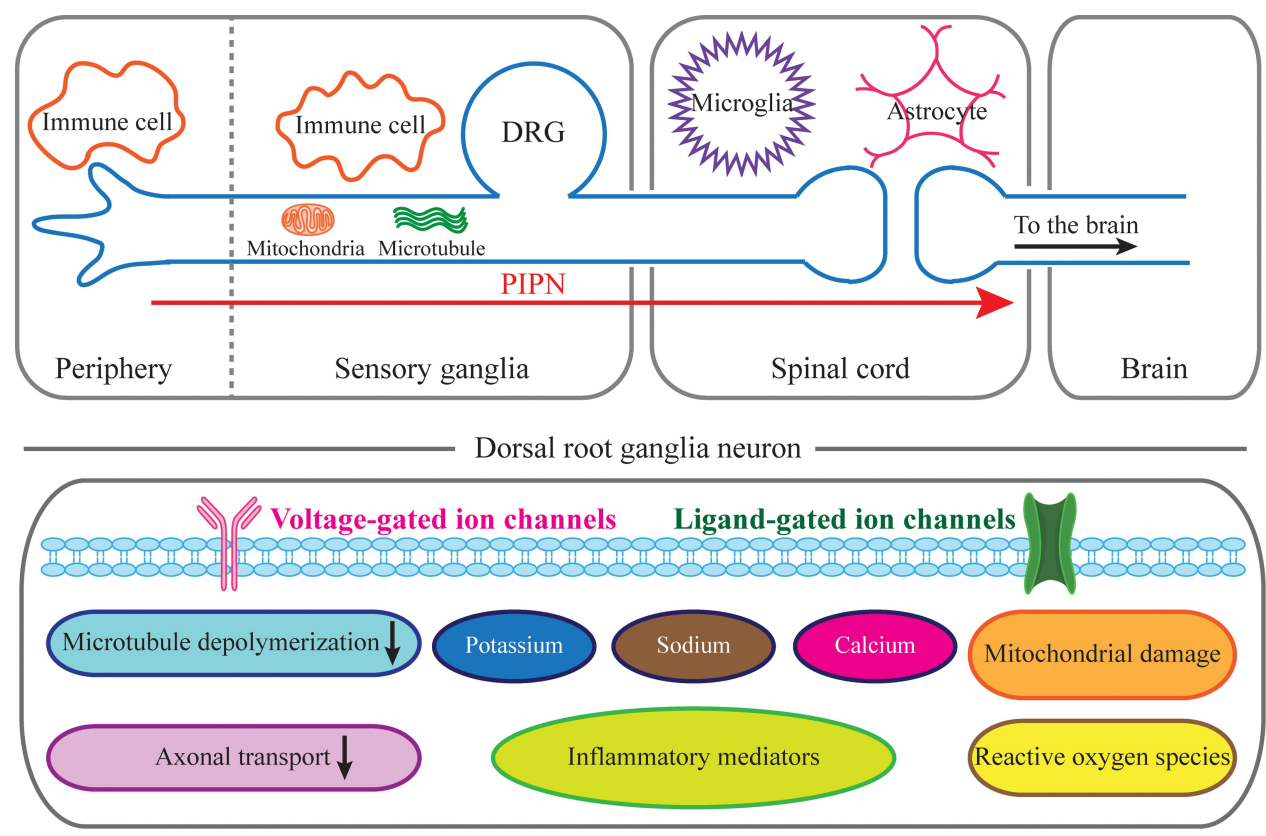

Figure I Pathology of paclitaxel-induced peripheral neuropathy (PIPN). The underlying mechanism leading to the occurrence and development of PIPN. Paclitaxel causes damage to distal nerve fibers and lead to painful peripheral neuropathy mainly by affecting ion channels, mitochondrial function, axonal transport and also by interfering with the neuro-immune response.

mitochondrial function by the administration of chemotherapeutic agents. ${ }^{38,39}$ Dysfunctional mitochondria lead to abnormal accumulation of reactive oxygen species (ROS) resulting in oxidative stress, which in turn increases mitochondrial damage and this vicious cycle of oxidative damage exists during the development of CIPN. ${ }^{40,41}$ In rodent models, paclitaxel-induced painful peripheral neuropathy and nociceptive sensation are in connection with the increased incidence of swollen and vacuolated mitochondria in the affected nerve axons. In DRG, paclitaxel treatment usually causes abnormal morphology of mitochondria with a typical swollen shape and altered cristae. ${ }^{42}$ The atypical (swollen and vacuolated) mitochondria are also seen in C-fibers and myelinated axons in rodent models of PIPN, which is probably associated with opening of the mitochondrial permeability transition pore. ${ }^{43}$ In addition, impaired mitochondrial respiration and ATP production induced by paclitaxel are shown in rat sciatic nerve samples, which may potentiate paclitaxel-evoked sensory peripheral neuropathy. ${ }^{44}$ Moreover, the development of paclitaxel-induced mechanical hyperalgesia was limited by a potent antioxidant melatonin through reducing mitochondrial damage in a rat model of PIPN. ${ }^{45}$

\section{Disruption of Axonal Transport}

Paclitaxel binds along the microtubules of neurons, stabilizes the microtubule lattice, affects their dynamic adaptation of the cytoskeleton, and blocks the polymerization of tubulin, leading to the inhibition of tubulin dynamics, axonal degradation and loss of epidermal innervation. ${ }^{46,47}$ Paclitaxel significantly reduces the axonal outgrowth, with distinctive morphological changes of axons. $^{42}$ Peripheral nerve biopsy indicated the pathological state of sensory axonal degeneration, secondary demyelination, and peripheral nerve fibers loss caused by paclitaxel. In addition, long-term paclitaxel treatment causes polar reconfiguration of microtubules, which in turn results in diverse degrees of alterations in organelles transport. ${ }^{46,48,49}$ In brief, PIPN is commonly characterized by axonal degeneration that is closely associated with distal sensory or sensorimotor fibers.

\section{Neuroinflammation}

Neuroinflammation is a complicated pathophysiological process that involves a series of distinct steps including infiltration of immune cells, activation of neuroglia, production of inflammatory chemokines and cytokines, and the following cascade reactions of the inflammatory mediators in the nervous system. ${ }^{38}$ Paclitaxel administration induces robust recruitment and accumulation of macrophages into DRG neurons and peripheral afferents, decreases the number of intraepidermal nerves, and increases the number of cutaneous Langerhans cells, suggesting neuro-immune interactions that might be 
involved. ${ }^{50,51}$ Besides, it is well documented that activation of spinal neuroglia is strongly linked to PIPN. Paclitaxel induces robust activation of microglia and astrocytes in the spinal cord, which contributes to the release of proinflammatory cytokines such as TNF- $\alpha$, IL- $1 \beta$ and IL6 , leading to spinal central sensitization and pain behavior. $^{52,53}$ On the other hand, cytokines such as IL-1 in turn play critical roles in modulating functions of neuroglia. PIPN was evoked in wild-type mice but not in mice that are deficient in IL-1 receptor. ${ }^{54}$ Of note, TLR4, as a vital pattern-recognition receptor that mediates immune pathways, has been implicated as a key factor for initiation of PIPN. ${ }^{55,56}$ Administration of TLR4 antagonist blocked paclitaxel effects on sensory neurons and prevented development of PIPN. ${ }^{55,57}$ In addition, paclitaxel-evoked mechanical allodynia may be associated with activation of the NOD-like receptor protein 3 (NLRP3) inflammasome pathway which potentiates the innate immunity and inflammatory responses. ${ }^{58-60}$

\section{Supraspinal Pathophysiology}

To date, most fundamental studies investigating mechanisms underlying genesis and development of PIPN have focused on the neural tissues of DRG, primary afferents and spinal cord, where PTX accumulates with relatively high concentrations following PTX treatment. ${ }^{61}$ In contrast, the brain, with the lowest distribution and concentration of PTX, has been rarely studied in the pathophysiology of PIPN. ${ }^{61,62}$ Recent studies support that alterations in certain areas of the brain following PTX administration are implicated in the occurrence and maintenance of PIPN. ${ }^{61-63}$ The anterior cingulate cortex (ACC) is a brain region involved in sensory perception and modulation of pain. ${ }^{64}$ During PIPN in rodents, dysregulation of the $\gamma$-aminobutyric acid (GABA) neurotransmitter system, which is involved in the pathogenesis of neuropathic pain, was confirmed in the ACC via observing a significant increase in gene expression of GABA transporter-1 (GAT-1). ${ }^{62,63}$ GAT-1 is the major transporter responsible for GABA uptake from the synapses in the brain. It has been confirmed that blockage of GAT-1 ameliorated PIPN, indicating a significant role of GAT-1 in the pathophysiology of PIPN. ${ }^{65}$ Besides, the activities of some key areas within the nociceptive neural circuitry in the brain, such as periaqueductal gray (PAG) and brainstem, were affected by PTX treatment, which in turn may contribute to the pathogenesis of PIPN. $^{61,66}$

\section{Acupuncture for PIPN Acupuncture Treatment}

Based on the methods of manipulation or stimulation, the general type of acupuncture in the treatment of PIPN is commonly classified as manual acupuncture (MA) and electroacupuncture (EA). In MA, needles are inserted into acupuncture points (acupoints) and manually manipulated to provoke a particular needling sensation of soreness, numbness, heaviness and distension called "De-Qi" which is essential to acupuncture analgesia, to achieve optimal therapeutic effects in patients. ${ }^{10,67,68}$ Typically used manipulation techniques in clinical practice mainly include lifting-thrusting (Figure 2A) and twisting-rotation (Figure 2B). MA-induced analgesia is mediated by all types of peripheral afferent fibers including $\mathrm{A} \beta, \mathrm{A} \delta$, and C-type afferents. ${ }^{10}$ In EA, transdermal electrical stimulation with different parameters is delivered to acupoints through needles connected to an electric stimulus (Figure 2C) to activate nerve fibers and produce analgesic effects. ${ }^{10,69}$ In comparison with MA, the key advantage of EA is that it can be applied consistently with adjustable standardized parameters (frequency, intensity and duration) to obtain certain therapeutic effect including analgesic action. ${ }^{67,70}$ The peripheral afferent mechanism underlying EA analgesia is mainly associated with activation of $A \beta / A \delta$-type afferents. ${ }^{10}$ The specific manipulations of MA and the electrical parameters of EA in treatment of PIPN will be explained in detail in the following
A

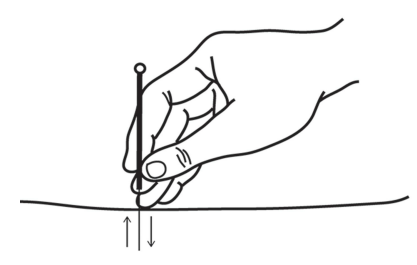

B

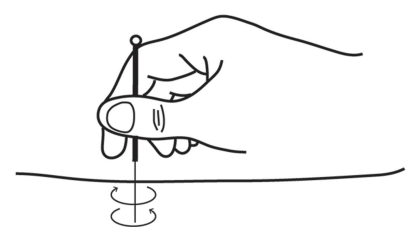

C

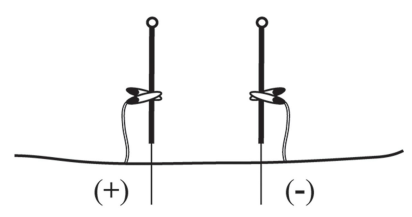

Figure 2 Acupuncture for paclitaxel-induced peripheral neuropathy (PIPN). (A) Manual acupuncture (MA) with lifting-thrusting method. (B) MA with twisting-rotating method. (C) Electroacupuncture (EA). 
chapters, as well as the potential mechanism underlying the action of MA and EA in relieving PIPN.

\section{Clinical Studies}

The relevant clinical literature in the past 10 years were reviewed and a summary of these clinical studies is shown in Table 1.

In a retrospective service evaluation, 18 patients were treated with MA for CIPN, and 2 of them with peripheral neuropathy induced by paclitaxel or docetaxel. ${ }^{71}$ Acupuncture was performed on these patients for 6 weeks using acupoints among SP6, ST36, LV3, LI4, BL60, and Ba-Feng/Ba-Xie, in which SP6, ST36, and
LV3 were the most commonly used. $82 \%$ of patients showed improvement in symptoms following their course of acupuncture, and some of them derived additional benefits from acupuncture treatment including less analgesic medication and better sleep. With regard to the patients suffering from neuropathy due to paclitaxel/docetaxel, all of them showed improved symptoms.

A pilot controlled nonrandomized study evaluated the therapeutic effect of acupuncture on 6 patients suffering from CIPN. ${ }^{72}$ They received a standard 10-week MA treatment on acupoints of ST34, Qi-Duan, and Ba-Feng. After acupuncture treatment, most of the patients (5 out of 6) including those with CIPN by docetaxel showed

Table I Characteristics of the Clinical Studies Involving the Use of Acupuncture in Taxane-Induced Peripheral Neuropathy

\begin{tabular}{|c|c|c|c|c|c|c|c|}
\hline Reference & $\begin{array}{l}\text { Cancer Type } \\
\text { (Number of } \\
\text { Patients) }\end{array}$ & $\begin{array}{c}\text { Neurotoxic } \\
\text { Agent }\end{array}$ & Intervention & Acupoints & $\begin{array}{l}\text { Duration } \\
\text { of } \\
\text { Treatment }\end{array}$ & Outcome & Results \\
\hline $\begin{array}{l}\text { Donald et al. } \\
(2011)^{71}\end{array}$ & Breast (2) & $\begin{array}{l}\text { Docetaxel/ } \\
\text { paclitaxel }\end{array}$ & MA & $\begin{array}{c}\text { SP6, ST36, LV3, } \\
\text { LI4, BL60, Ba-Feng, } \\
\text { Ba-Xie }\end{array}$ & 6 weeks & $\begin{array}{c}\text { Evaluation on } \\
\text { efficacy }\end{array}$ & $\begin{array}{l}\text { Improved } \\
\text { symptoms }\end{array}$ \\
\hline $\begin{array}{l}\text { Schroeder } \\
\text { et al. }(201 \mathrm{I})^{72}\end{array}$ & Breast (I) & $\begin{array}{c}\text { Docetaxel / } \\
\text { doxorubicin / } \\
\text { cyclophosphamide }\end{array}$ & MA & $\begin{array}{c}\text { ST34, Qi-Duan, } \\
\text { Ba-Feng }\end{array}$ & 10 weeks & NCS & $\begin{array}{l}\text { Improved } \\
\mathrm{NCV}\end{array}$ \\
\hline $\begin{array}{l}\text { Lu et al. } \\
(2012)^{73}\end{array}$ & Ovarian (6) & $\begin{array}{l}\text { Paclitaxel / } \\
\text { carboplatin }\end{array}$ & $M A$ and $E A$ & $\begin{array}{l}\text { LII I, LI4, PC6, } \\
\text { GV20, SPI0, ST36, } \\
\text { SP6, K3, LR3 }\end{array}$ & $\begin{array}{l}\text { Over } 4 \\
\text { weeks }\end{array}$ & $\begin{array}{l}\text { QLQ-C30, } \\
\text { QLQ-OV28 }\end{array}$ & $\begin{array}{l}\text { Improved } \\
\text { scores }\end{array}$ \\
\hline $\begin{array}{l}\text { Greenlee } \\
\text { et al. }(2016)^{74}\end{array}$ & Breast (48) & $\begin{array}{l}\text { Paclitaxel, or } \\
\text { combined with } \\
\text { docetaxel }\end{array}$ & EA & $\begin{array}{l}\text { GB34, ST36, LI4, } \\
\text { LII0, L3, L5, C5, } \\
\text { C7 }\end{array}$ & 12 weeks & $\begin{array}{l}\text { BPI-SF, NPS, } \\
\text { FACT-NTX }\end{array}$ & $\begin{array}{c}\text { Unidentified } \\
\text { efficacy }\end{array}$ \\
\hline $\begin{array}{l}\text { Ben-Horin } \\
\text { et al. }(2017)^{75}\end{array}$ & Breast (2) & $\begin{array}{l}\text { Docetaxel/ } \\
\text { paclitaxel }\end{array}$ & $\begin{array}{c}\text { MA and } \\
\text { Reflexology }\end{array}$ & Jing-Well & $\begin{array}{c}\text { About } \\
5.4-10.8 \\
\text { weeks }\end{array}$ & $\begin{array}{c}\text { Neuropathy } \\
\text { grade }\end{array}$ & $\begin{array}{l}\text { Improved } \\
\text { symptoms }\end{array}$ \\
\hline $\begin{array}{l}\text { Bao et al. } \\
(2018)^{76}\end{array}$ & Breast (27) & Paclitaxel & MA & $\begin{array}{l}\text { Auricular points, } \\
\text { LI4, TE5, LIII, } \\
\text { ST40, Ba-Feng, }\end{array}$ & Not known & $\begin{array}{c}\text { CIPN grade, } \\
\text { FACT/GOG- } \\
\text { Ntx, NPS }\end{array}$ & $\begin{array}{c}\text { Prevention } \\
\text { of high CIPN } \\
\text { grade }\end{array}$ \\
\hline $\begin{array}{l}\text { Jeong et al. } \\
(2018)^{77}\end{array}$ & Breast (10) & Taxane & MA & $\begin{array}{l}\text { LI4, LII I, ST36, } \\
\text { LV3, Ba-Feng, Ba- } \\
\text { Xie }\end{array}$ & 4 weeks & $\begin{array}{l}\text { NPSI, NCS, } \\
\text { SF-36 }\end{array}$ & $\begin{array}{l}\text { Attenuated } \\
\text { neuropathy }\end{array}$ \\
\hline $\begin{array}{l}\text { Molassiotis } \\
\text { et al. }(2019)^{78}\end{array}$ & $\begin{array}{l}\text { Breast, colorectal, } \\
\text { head and neck, } \\
\text { ovarian, myeloma } \\
\text { (24) }\end{array}$ & $\begin{array}{l}\text { Paclitaxel/ } \\
\text { docetaxel }\end{array}$ & MA & $\begin{array}{l}\text { LI4, LIII, PC7, } \\
\text { TE5, SP6, ST36, } \\
\text { LV3, ST4I, Ba- } \\
\text { Feng, Ba-Xie }\end{array}$ & 8 weeks & $\begin{array}{c}\text { BPI, NCS } \\
\text { FACT/GOG- } \\
\text { Ntx, TNSc, } \\
\text { CTCAE }\end{array}$ & $\begin{array}{l}\text { Improved } \\
\text { symptoms }\end{array}$ \\
\hline
\end{tabular}

Abbreviations: MA, manual acupuncture; EA, electroacupuncture; NCS, nerve conduction studies; NCV, nerve conduction velocity; QLQ-C30, quality of life questionnaire-core 30 item; QLQ-OV28, quality of life questionnaire-ovarian module-28 item; BPI-SF, brief pain inventory-short form; FACT-NTX, functional assessment of cancer therapy-taxane neurotoxicity subscale; CIPN, chemotherapy-induced peripheral neuropathy; FACT/GOG-Ntx, functional assessment of cancer therapy/gynecologic oncology group-neurotoxicity; NPS, neuropathic pain scale; NPSI, neuropathic pain symptom inventory; SF-36, the 36-item short form healthy survey; BPI, the brief pain inventory; TNSc, total neuropathy score-clinical version; CTCAE, common toxicity criteria for adverse events. 
improved nerve conduction velocity (NCV) and mean amplitude of nerve conduction studies (NCS) which revealed the improvement in the impaired axon and myelin sheath of the sensory nerve caused by CIPN.

In a pilot randomized sham-controlled trial, 21 patients receiving chemotherapy (primarily carboplatin and paclitaxel) accepted either verum or sham acupuncture (11 were in the verum arm and 10 were in the sham arm) with 10 sessions over 4 weeks. ${ }^{73}$ In verum acupuncture group, patients received both MA and EA with selected acupoints among LI11, LI4, PC6, GV20, SP10, ST36, SP6, K3, and LR3 accordingly. For the sham acupuncture protocol, 5 non-acupuncture points in the proximity of verum points but off the meridians were used and manipulated by the same acupuncturists in the verum acupuncture group. Scores from the European Organization for Research and Treatment of Cancer-Quality of Life Questionnaire-Core 30 Item (EORTC-QLQ-C30) revealed that patients in the verum acupuncture group had slightly better scores in relieving pain, insomnia, and constipation than patients in the sham acupuncture arm, of which constipation was remarkably different between the two arms. Scores from Quality of Life Questionnaire-Ovarian Module-28 Item (QLQ-OV28) showed significantly better subscores in hormonal and peripheral neuropathy in the verum acupuncture arm than the sham. The results from both questionnaires above indicate the improved quality of life in patients with CIPN after acupuncture treatment.

Another randomized sham-controlled pilot trial was conducted to investigate the effect of EA on CIPN in breast cancer patients undergoing taxane chemotherapy. ${ }^{74}$ Patients were scheduled to receive standardized protocols of true EA or sham EA weekly for 12 weeks. Acupuncture needles were inserted into acupoints including GB34, ST36, LI4, LI10, L3, L5, C5, and C7, and connected to an electro-stimulator with $2 \mathrm{~Hz}$ of mixed electrical impulse. In the sham EA group, needles were placed to touch but not penetrate the skin where none of any true acupoints were included. The therapeutic effect of EA and sham EA was assessed by using Brief Pain InventoryShort Form (BPI-SF), Neuropathic Pain Scale (NPS), and Functional Assessment of Cancer Therapy-Taxane neurotoxicity subscale (FACT-NTX). The conclusion of this study was that patients receiving EA had a slower recovery in CIPN symptoms than those in the sham EA group. But it is important to recognize that this trial focused on the prevention of PIPN, which was different from others that placed emphasis on the management of post- chemotherapy PIPN. In the study, there was no difference in neuropathy symptoms between true EA and sham EA before or at 12 weeks, namely, during the period of EA treatment. Nevertheless, the difference in pain between treatment arms occurred only at the 16th week, when the EA treatment had been over for 4 weeks. Furthermore, the trial is limited by small sample size. Therefore, it remains hard to draw conclusions concerning the effect of EA here, and more studies are needed.

A retrospective analysis was performed to evaluate the efficacy of acupuncture and reflexology in the treatment of CIPN in patients with breast cancer. ${ }^{75}$ Two of the 28 patients in total enrolled into the study were given chemotherapy protocol involving paclitaxel and docetaxel. Patients received a therapeutic protocol called the Acupuncture and Reflexology Treatment for Neuropathy (ART-N) protocol which included 1 to 2 weekly sessions of MA with 10.8 sessions on average and reflexology therapy. The major acupoints in application were JingWell points in hands and feet. Different grades classified based on severities of sensory and motor neuropathies were used to assess the therapeutic efficacy of ART-N. After treatment, $93 \%$ of patients had complete resolution of CIPN symptoms, indicating the potential of the joint protocol of acupuncture and reflexology to improve CIPN symptoms in breast cancer patients.

Bao et al. ${ }^{76}$ conducted a phase IIA single-arm clinical trial to evaluate the preliminary efficacy of acupuncture in relieving PIPN in breast cancer patients receiving paclitaxel. MA was performed in patients with an acupoints protocol consisting of auricular points, Ba-Feng points, and body points (LI4, TE5, LI11, ST40). To assess acupuncture's effects in attenuating PIPN, some evaluation indexes were collected weekly during the intervention which included National Cancer Institute-Common Toxicity Criteria for Adverse Events (NCI-CTCAE) CIPN grade, Functional Assessment of Cancer Therapy/ Gynecologic Oncology Group-Neurotoxicity (FACT/ GOG-Ntx), and NPS. The result showed that most of the patients (26 out of 27) that developed grade II CIPN completed paclitaxel chemotherapy without developing higher CIPN grade after MA treatment. Besides, FACT/ GOG-Ntx and NPS scores were stable during acupuncture treatment while continuing weekly paclitaxel.

A prospective single-arm pilot trial and an observational study explored the feasibility and safety of acupuncture in the treatment of taxane-evoked peripheral neuropathy in 10 patients with breast cancer. ${ }^{77}$ 
Acupuncture needles were gently manipulated on a total of 6 acupoints (LI4, LI11, ST36, LV3, Ba-Feng, and Ba-Xie) to achieve De-Qi sensation. Twelve MA sessions were delivered for 4 weeks. The severity of CIPN was measured by using the Neuropathic Pain Symptom Inventory (NPSI) and Nerve Conduction Study (NCS) of extremities. The quality of life was evaluated by using the 36-Item Short Form Healthy Survey (SF-36). 42.9\% of patients showed attenuated sensory neuropathy. In addition, all of the patients assessed by the SF-36 showed improved quality of life at the end of acupuncture treatment. There were no serious side effects during the entire treatment period.

The last study included was a randomized assessorblinded wait-list-controlled trial of 48 cancer patients who endured neurotoxic chemotherapy which contained 24 patients suffering from PIPN due to paclitaxel and docetaxel. $^{78}$ The acupuncture intervention was carried out twice a week for 8 weeks in total with a collection of acupoints located in upper limbs (LI4, LI11, PC7, TE5, and $\mathrm{Ba}-\mathrm{Xie}$ ) and/or lower limbs (SP6, ST36, LV3, ST41, and Ba-Feng). The Brief Pain Inventory (BPI), FACT/ GOG-Ntx, the 7-domain Total Neuropathy Score-Clinical Version (TNSc), the National Cancer Institute-Common Toxicity Criteria for Adverse Events (CTCAE) and NCS were applied to measure pain intensity, quality of life, neuropathy scores, CIPN grade and nerve function, respectively. Patients receiving acupuncture therapy obtained improved symptoms in pain, neurotoxicity and distress which suggested that acupuncture could be a promising intervention in the treatment of CIPN.

The clinical studies described above have several limitations. Some trials were conducted without control of variables, $^{71}$ as well as no baseline data and validated questionnaires. Thus, the findings demonstrated in such trials were the subjective opinions from patients at one time point and the placebo effect may play a role here. Moreover, the clinical assessment tool in some studies is not fully appropriate to evaluate PIPN. For instance, using the QLQ-OV28 to measure numbness and tingling in the extremities is less comprehensive compared with the FACT-NTX subscale used in another studies. ${ }^{73,74,76,78}$ Likewise, using CTCAE as one of the objective assessments can misdiagnose CIPN. ${ }^{72}$ Some studies are singlearm trials and deficient in randomization and control which can generate uncontrolled biases and cannot eliminate placebo effects. ${ }^{75-77}$ In addition, since all of the studies are limited by small sample size, it is difficult to obtain definite, solid and firm conclusions from the available data.

\section{Basic Studies}

Acupuncture attenuated paclitaxel-evoked painful peripheral neuropathy in animal models. A summary of these basic studies is shown in Table 2 .

A study in a PIPN model in male Sprague-Dawley rats shows that EA at bilateral GB30 for 30 min every other day relieved paclitaxel-evoked mechanical allodynia and hyperalgesia. ${ }^{79}$ EA at a low frequency $(10 \mathrm{~Hz})$ elicited more potent analgesic effects than EA at a high frequency $(100 \mathrm{~Hz})$. The application of three spinal opioid receptors ( $\mu, \delta$ and $\kappa$ ) antagonists reversed the EA-induced analgesic effect, which indicated that the activation of these spinal opioid receptors may potentiate the anti-nociceptive action of EA at low frequency. It is also in accord with a previous study which demonstrated that different EA frequencies determined different types of opioid peptide released in the central nervous system. ${ }^{80}$

In another PIPN model, male ICR mice with neuropathic pain received EA treatment at bilateral ST36 acupoints for $30 \mathrm{~min}$ once every 2 days for a total of 14 days. ${ }^{81}$ Repeated EA stimulation significantly ameliorated paclitaxel-induced mechanical allodynia and thermal hyperalgesia, and suppressed phosphorylation of the $\mathrm{N}$-methyl-D aspartate (NMDA) receptor NR2B enhanced by paclitaxel in the spinal cord, suggesting the potent analgesic effect elicited by EA. Respective spinal administration of opioid receptor antagonist (naloxone), $\alpha 2$-adrenoceptor antagonist (idazoxan), $\beta$-adrenoceptor antagonist (propranolol), but not $\alpha 1$-adrenoceptor antagonist (prazosin) blocked EA-evoked antinociceptive effect against neuropathic pain, indicating the important roles of the spinal opioid receptor, $\alpha 2$ - and $\beta$-adrenoceptors in mediating EA analgesic actions. Besides, bee venom acupuncture (BVA), a special type of acupuncture used in traditional Korean medicine, significantly relieved mechanical hyperalgesia caused by paclitaxel via subcutaneously injecting bee venom into LI11 or ST36 acupoints. $^{82}$ The analgesic effect of BVA was also mediated by spinal $\alpha 2$ adrenoceptor, which was verified by the application of the $\alpha 2$-adrenoceptor antagonist idazoxan.

The therapeutic efficacy of a combination therapy consisting of gabapentin (GBT) and EA against PIPN was investigated in young male adult C57BL/6 mice with neuropathic pain produced by paclitaxel administration. ${ }^{83}$ 
Table 2 Characteristics of the Basic Studies Involving the Use of Acupuncture in Paclitaxel-Induced Peripheral Neuropathy

\begin{tabular}{|c|c|c|c|c|c|c|}
\hline Reference & $\begin{array}{l}\text { Animals (Body } \\
\text { weight/Age) }\end{array}$ & $\begin{array}{c}\text { Agent } \\
\text { (Injection) }\end{array}$ & Intervention & Acupoints & $\begin{array}{c}\text { Stimulus } \\
\text { Parameters }\end{array}$ & Results \\
\hline $\begin{array}{l}\text { Meng et al. } \\
(2011)^{79}\end{array}$ & Rats $(250-270 \mathrm{~g})$ & $\begin{array}{l}\text { Paclitaxel } \\
\text { (IP) }\end{array}$ & EA & GB30 & $\begin{array}{l}10 \text { or } 100 \mathrm{~Hz}, 2 \mathrm{~mA} \text {, } \\
0.4 \mathrm{~ms}, 30 \mathrm{~min}\end{array}$ & $\begin{array}{c}\text { EA at } 10 \mathrm{~Hz} \text { inhibits painful response } \\
\text { better than } 100 \mathrm{~Hz}\end{array}$ \\
\hline $\begin{array}{l}\text { Choi et al. } \\
(20 \mid 5)^{81}\end{array}$ & Mice (20-25 g) & $\begin{array}{l}\text { Paclitaxel } \\
\text { (IP) }\end{array}$ & EA & ST36 & $\begin{array}{c}2 \mathrm{~Hz}, 2 \mathrm{~mA}, 0.15 \mathrm{~ms}, \\
30 \mathrm{~min}\end{array}$ & Attenuated painful response \\
\hline $\begin{array}{l}\text { Choi et al. } \\
(2017)^{82}\end{array}$ & Rats $(180-210 \mathrm{~g})$ & $\begin{array}{l}\text { Paclitaxel } \\
\text { (IP) }\end{array}$ & BVA & LIII, ST36 & $\begin{array}{l}\text { BV was injected at } \\
\text { LIII I or ST36 }\end{array}$ & $\begin{array}{c}\text { Relieved hyperalgesia, suppressed } \\
\text { SWDRN }\end{array}$ \\
\hline $\begin{array}{l}\text { Kim et al. } \\
(2017)^{83}\end{array}$ & Mice (6-8 weeks) & $\begin{array}{l}\text { Paclitaxel } \\
\text { (IP) }\end{array}$ & GBT, EA & ST36 & $\begin{array}{l}\text { GBT: IP; EA: } 2 \mathrm{~Hz} \\
0.3 \mathrm{~ms}, 20 \mathrm{~min}\end{array}$ & $\begin{array}{c}\text { The combination of GBT and EA has } \\
\text { a better analgesic action }\end{array}$ \\
\hline $\begin{array}{l}\text { Zhang et al. } \\
(2017)^{84}\end{array}$ & Rats $(250-270 \mathrm{~g})$ & $\begin{array}{l}\text { Paclitaxel } \\
\text { (IP) }\end{array}$ & EA & GB30 & $\begin{array}{c}10 \mathrm{~Hz}, 2 \mathrm{~mA}, 0.4 \mathrm{~ms}, \\
30 \mathrm{~min}\end{array}$ & $\begin{array}{c}\text { Alleviated mechanical allodynia and } \\
\text { hyperalgesia }\end{array}$ \\
\hline $\begin{array}{l}\text { Zhang et al. } \\
(2018)^{85}\end{array}$ & Mice (18-22 g) & $\begin{array}{l}\text { Paclitaxel } \\
\text { (IP) }\end{array}$ & EA & GB30 & $2 \mathrm{~Hz}, \mathrm{I} \mathrm{mA}, 30 \mathrm{~min}$ & Alleviated neuropathic pain \\
\hline $\begin{array}{l}\text { Li et al. } \\
(2019)^{86}\end{array}$ & Rats $(180-220 \mathrm{~g})$ & $\begin{array}{l}\text { Paclitaxel } \\
\text { (IP) }\end{array}$ & EA & ST36, BL60 & $\begin{array}{c}2 \mathrm{~Hz}, 0.5-1.5 \mathrm{~mA}, 0.2 \\
\mathrm{~ms}, 30 \mathrm{~min}\end{array}$ & Alleviated pain hypersensitivities \\
\hline $\begin{array}{l}\text { Zhao et al. } \\
(2019)^{24}\end{array}$ & Rats $(200-250 \mathrm{~g})$ & $\begin{array}{l}\text { Paclitaxel } \\
\text { (IP) }\end{array}$ & EA & PC6, PC5 & $\begin{array}{c}2 \mathrm{~Hz}, 2 \mathrm{~mA}, 0.5 \mathrm{~ms}, \\
20 \mathrm{~min}\end{array}$ & $\begin{array}{l}\text { Attenuated mechanical and thermal } \\
\text { hypersensitivity }\end{array}$ \\
\hline $\begin{array}{l}\text { Zhao et al. } \\
(2020)^{87}\end{array}$ & Rats $(120-150 \mathrm{~g})$ & $\begin{array}{c}\text { Paclitaxel } \\
\text { (IP) }\end{array}$ & EA & ST36 & $10 \mathrm{~Hz}, 1 \mathrm{~mA}, 30 \mathrm{~min}$ & Attenuated mechanical allodynia \\
\hline
\end{tabular}

Abbreviations: IP, intraperitoneal; EA, electroacupuncture; BVA, bee venom acupuncture; SWDRN, spinal wide dynamic range neurons; GBT, gabapentin.

Either GBT injection with low, median, high dose, or EA alone produced an analgesic effect against cold and mechanical allodynia. The combined use of EA and GBT with low dose exerted a synergistic anti-nociceptive effect which resulted in a greater and longer analgesic action than separate treatment with each agent alone. In addition, spinal administration of an opioid receptor antagonist (naloxone) or $\alpha 2$ adrenoceptor antagonist (idazoxan) blocked the analgesic effect of the combination treatment with EA and GBT, implying the important role of opioid and/or $\alpha 2$ adrenergic receptors in mediating the therapeutic action produced by the combined therapy.

Moreover, EA has been reported to attenuate paclitaxelinduced neuropathic pain by activating 5-hydroxytryptamine 1A (5-HT1A) receptors whereas inhibiting $\mathrm{Ca}^{2+} /$ calmodulindependent protein kinase II (CaMKII) in the spinal cord. ${ }^{84} \mathrm{EA}$ stimulation $(10 \mathrm{~Hz}, 2 \mathrm{~mA}, 0.4 \mathrm{~ms})$ was applied in a rat model of PIPN for $30 \mathrm{~min}$ once every other day. The PIPN was significantly alleviated by EA treatment and the alleviation of mechanical allodynia/hyperalgesia lasted up to 3 weeks after the end of EA. The potential mechanism underlying EA's analgesic action may be associated with its down- regulation of CaMKII and up-regulation of 5-HT1A receptors in the spinal cord, since EA inhibited the spinal phosphorylation of CaMKII which is involved in pain at the spinal cord, whereas both EA-produced analgesic effect and the inhibited CaMKII by EA were reversed by using 5-HT1A receptor antagonist.

A study using both wild-type and type 2 cannabinoid receptor $(\mathrm{CB} 2 \mathrm{R})$ receptor gene knockout $(\mathrm{KO})$ mice revealed the role of $C B 2 R$ in mediating EA's antinociceptive effect. ${ }^{85}$ The PIPN models established in wildtype and $\mathrm{CB} 2 \mathrm{R} \mathrm{KO}$ mice respectively were intervened by EA stimulation ( $2 \mathrm{~Hz}, 1 \mathrm{~mA})$ at bilateral GB30 for $30 \mathrm{~min}$ once a day for a total of 7 days. EA treatment significantly increased mechanical pain threshold, meanwhile it upregulated CB2R expression, but down-regulated levels of NLRP3, Caspase-1 and IL-1 $\beta$ in sciatic nerve tissue. Whereas in terms of CB2R KO mice, EA exerted effects neither on mechanical hypersensitivity nor on related protein expressions that are mentioned above, indicating that the analgesic action of EA could be mediated by peripheral $\mathrm{CB} 2 \mathrm{R}$ and might be related to the regulation of NLRP3 inflammasome signal pathway as well. 
Of note, the suppression of specific ligand-gated ion channels, such as TLR4 and TRPV1, potentiated the alleviated effect of EA against paclitaxel-induced pain hypersensitivities. ${ }^{86}$ In a rat model of paclitaxel-produced neuropathic pain, EA at bilateral ST36 and BL60 acupoints $(2 \mathrm{~Hz}, 0.5-1.5 \mathrm{~mA}, 0.2 \mathrm{~ms})$ for $30 \mathrm{~min}$ once daily for 7 consecutive days robustly and persistently attenuated paclitaxel-induced hyperalgesia. At the same time, EA inhibited the TRPV1 and TLR4 activities in DRG neurons and downstream signaling MyD88 that was enhanced by paclitaxel, as well as suppressed neuroglia activation in the spinal cord. In addition, the analgesic effects of EA on hyperalgesia was mimicked by pharmacological blocking of TRPV1, but was reversed by TRPV1 agonist capsaicin. These results are consistent with another study which gave special attention to the role of spinal glia and TLR4/NF$\kappa B$ pathway in EA-induced analgesic effect. ${ }^{87}$ In the study, EA treatment $(10 \mathrm{~Hz}, 1 \mathrm{~mA}, 30 \mathrm{~min})$ was applied at bilateral ST36 acupoints in a rat model of PIPN once every other day for 2 weeks. EA therapy significantly ameliorated the mechanical allodynia produced by paclitaxel in both hind paws of rats, along with the inhibition of spinal microglia and astrocytes, as well as the downregulation of both TLR4/NF- $\mathrm{kB}$ signals and proinflammatory cytokines (TNF- $\alpha$ and IL-1 $\beta$ ) by EA in the spinal cord.

The transcription factor nuclear factor-like 2-antioxidant response element (Nrf2-ARE) regulates antioxidant proteins and protects against oxidative stress which is involved in PIPN. ${ }^{24}$ Zhao et al. showed that EA $(2 \mathrm{~Hz}, 2$ $\mathrm{mA}, 0.5 \mathrm{~ms}$ ) at PC6 and PC5 acupoints in a rat model of paclitaxel-produced neuropathic pain attenuated mechanical and thermal hypersensitivity through largely restoring levels of Nrf2-ARE/superoxide dismutases (SOD), inhibiting oxidative stress (e.g. inhibition of 8 -iso PGF2 $\alpha$,
8-OHdG) and down-regulating pro-inflammatory cytokines in the DRG, thereby indicating the beneficial role of EA in regulation of neuropathic pain evoked by paclitaxel and also providing potential alternative options to combine EA with therapeutic medications to manage pain symptoms in future clinical practice.

In brief, the mechanisms of acupuncture on attenuating paclitaxel-induced neuropathic pain have been studied mainly at peripheral and spinal levels but not at supraspinal level by using rodent models of PIPN to date. A variety of bioactive substances are involved in the analgesic action of acupuncture against PIPN, including various neurotransmitters, multiple receptors, different types of enzymes and molecules (Table 3 ).

In addition, the neuroprotective effects of acupuncture have been demonstrated in many neurological disorders, involving its regulation of signaling pathways of endogenous biological mediators, especially the protein family of neurotrophic factors. ${ }^{88}$ For instance, in a rat model of depression, acupuncture treatment significantly up-regulates mRNA and protein expressions of brain-derived neurotrophic factor (BDNF) in the frontal cortex and hippocampus of rats which contributes greatly to the antidepressant action of acupuncture. ${ }^{89}$ Besides, in ischemia and reperfusion (I/R) injured rats, EA increased localized expression of BDNF in cortex and striatum thus promoting its neuroprotective effect against $\mathrm{I} / \mathrm{R}$ injury. ${ }^{90}$ Although there is no direct evidence supporting the neuroprotective action of acupuncture in PIPN, the regulation of neurotrophic factors might be one of the possible neuroprotective mechanisms potentiating the therapeutic effect of acupuncture on PIPN, and that requires further investigations in the future.

In the review, we began with the presentation of the basic pathology of PIPN, and then briefly made an introduction of acupuncture treatment that was followed by an

Table 3 Summary of Possible Mechanisms Involved in Acupuncture Attenuation of PIPN in Animal Models

\begin{tabular}{|c|c|c|c|c|c|}
\hline $\begin{array}{l}\text { Level of } \\
\text { Control }\end{array}$ & Neurotransmitters & Receptors & $\begin{array}{c}\text { Key Enzymel } \\
\text { Molecules }\end{array}$ & $\begin{array}{c}\text { Target } \\
\text { Nervel } \\
\text { Cell }\end{array}$ & References \\
\hline Peripheral & $\begin{array}{c}\text { Caspase-I, TNF- } \alpha \text {, IL-I } \beta \text {, IL- } \\
\text { 6, NOX4, NQOI, Nrf2 }\end{array}$ & CB2R, TLR4, TRPVI & $\begin{array}{l}\text { MyD88, NLRP3, SOD, } \\
\text { 8-iso PGF2 } \alpha, 8-O H d G\end{array}$ & $\begin{array}{c}\text { Sciatic } \\
\text { nerve, DRG }\end{array}$ & {$[24,85,86]$} \\
\hline $\begin{array}{l}\text { Spinal } \\
\text { cord }\end{array}$ & TNF- $\alpha$, IL-I $\beta$ & $\begin{array}{l}\text { Opioid receptors, adrenoceptors, } \\
\text { NMDA receptors, TLR4, 5-HTIAR }\end{array}$ & CaMKII, NF-KB & $\begin{array}{l}\text { Astrocytes, } \\
\text { microglia }\end{array}$ & {$[79,8 \mathrm{I}-84,86,87]$} \\
\hline
\end{tabular}

Abbreviations: NOX4, NADPH oxidase 4; NQOI, NADPH quinone oxidoreductase-I; Nrf2, factor nuclear factor-like 2; CB2R, type 2 cannabinoid receptor; TLR4, tolllike receptor 4; TRPVI, transient receptor potential vallinoid I; MyD88, myeloid differentiation primary response 88; NLRP3, nod-like receptor protein 3; SOD, superoxide dismutases; 8-iso PGF2 $\alpha$, 8-isoprostaglandin F2 $\alpha$; 8-OHdG, 8-hydroxy-2'-deoxyguanosine; DRG, dorsal root ganglion; NMDA, N-methyl-D aspartate; 5-HTIAR, 5-hydroxytryptamine IA receptor; CaMKII, calmodulin-dependent protein kinase II; NF-kB, nuclear factor-kappa B. 
emphasis on the clinical and basic studies concerning the therapeutic effect of acupuncture in treatment of PIPN and the potential mechanisms involved. In the following section, we present the summary of the current review, as well as demonstrate the limitations and perspectives to enlighten further studies in the future.

\section{Conclusion and Perspectives}

It is difficult for patients with PIPN to access satisfactory treatment in the existing mainstream medicine, since effective therapeutic strategies available for this syndrome are quite limited. Acupuncture, as one of the alternative complementary therapies, is well-known for its efficacies in attenuating pain symptoms. Novel attempts using acupuncture have been reported to ameliorate paclitaxelinduced neuropathic pain in both clinical and basic studies.

Based on the clinical findings in existence, acupuncture remedy used alone or as a co-treatment intervention is estimated to have potential therapeutic effect in treating symptoms of PIPN with particular advantages to relieve pain and improve quality of life. However, the available clinical studies have limitations of small sample size and insufficient design, thus, large multicenter, randomized and controlled clinical trials with optimal designs are needed to further evaluate the effectiveness and clinical roles of acupuncture in treating PIPN in future. Of note, cancer patients receiving chemotherapy often suffer from mood disorders such as depression and anxiety, which are also the common comorbidities among patients experiencing PIPN. In turn, depression and anxiety can increase severity of PIPN, resulting in delayed recovery and reduced therapeutic efficacy. Acupuncture is widely considered to be a potential effective therapy in treatment of depression and anxiety but has been involved in very limited studies concerning emotional disorders during PIPN, so further exploration is called for.

Animal studies have revealed some possible mechanisms underlying the analgesic action of acupuncture against PIPN, but the available evidence is limited and is also restricted to the peripheral and spinal levels, therefore further basic studies are required to explore the profound mechanistic underpinnings of acupuncture in treatment of PIPN in the future research. Emerging evidence obtained recently by advanced detection methods, such as 3-dimensional neuroimaging, suggests the alterations in certain areas of brain following PTX treatment are implicated in the pathogenesis of PIPN. Thus the involvement of brain areas in the pathophysiology of PIPN may raise more concerns in the future. As far as we know, no studies have reported the regulatory effect of acupuncture on brain function and cerebral pathophysiology during PIPN, in view of which, more investigations are required to focus on the action of acupuncture in the brain following PTX administration.

\section{Author Contributions}

Conceptualization, Y.-X.Z. and B.Z.; writing-original draft preparation, Y.-X.Z.; writing-review and editing, Y.-X.Z., X.-C.Y., J.-H.G., M.-J.Y. and B.Z. All authors made substantial contributions to conception and design, acquisition of data, or analysis and interpretation of data; took part in drafting the article or revising it critically for important intellectual content; agreed to submit to the current journal; gave final approval of the version to be published; and agree to be accountable for all aspects of the work.

\section{Funding}

This work was supported by Beijing Natural Science Foundation (7202141 to Y.-X. Z.), Fundamental Research Funds for the Central Public Welfare Research Institutes (201814009 and ZZ13-YQ-067 to Y.-X. Z.) and National Natural Science Foundation of China Research Grants (81202763 to Y.-X. Z., 81674075 to B.Z.).

\section{Disclosure}

The authors report no conflicts of interest in this work.

\section{References}

1. Sisignano M, Baron R, Scholich K, Geisslinger G. Mechanism-based treatment for chemotherapy-induced peripheral neuropathic pain. Nat Rev Neurol. 2014;10(12):694-707. doi:10.1038/nrneurol.2014.211

2. Hershman DL, Lacchetti C, Dworkin RH, et al. Prevention and management of chemotherapy-induced peripheral neuropathy in survivors of adult cancers: American Society of Clinical Oncology clinical practice guideline. J Clin Oncol. 2014;32(18):1941-1967. doi:10.1200/JCO.2013.54.0914

3. Travis LB, Fossa SD, Sesso HD, et al. Chemotherapy-induced peripheral neurotoxicity and ototoxicity: new paradigms for translational genomics. J Natl Cancer Inst. 2014;106(5):dju044. doi:10.1093/jnci/dju044

4. Park SB, Goldstein D, Krishnan AV, et al. Chemotherapy-induced peripheral neurotoxicity: a critical analysis. CA Cancer J Clin. 2013;63(6):419-437. doi:10.3322/caac.21204

5. Grisold W, Cavaletti G, Windebank AJ. Peripheral neuropathies from chemotherapeutics and targeted agents: diagnosis, treatment, and prevention. Neuro Oncol. 2012;14(Suppl 4):iv45-iv54. doi:10.1093/ neuonc/nos 203

6. Rowinsky EK, Donehower RC. Paclitaxel (taxol). $N$ Engl J Med. 1995;332(15):1004-1014. doi:10.1056/NEJM199504133321507

7. Sekiguchi F, Domoto R, Nakashima K, et al. Paclitaxel-induced HMGB1 release from macrophages and its implication for peripheral neuropathy in mice: evidence for a neuroimmune crosstalk. Neuropharmacology. 2018;141:201-213. doi:10.1016/j.neuropharm.2018.08.040 
8. Starobova H, Vetter I. Pathophysiology of chemotherapy-induced peripheral neuropathy. Front Mol Neurosci. 2017;10:174. doi:10.3389/fnmol.2017.00174

9. Goldman N, Chen M, Fujita T, et al. Adenosine A1 receptors mediate local anti-nociceptive effects of acupuncture. Nat Neurosci. 2010;13 (7):883-888. doi:10.1038/nn.2562

10. Zhao ZQ. Neural mechanism underlying acupuncture analgesia. Prog Neurobiol. 2008;85(4):355-375. doi:10.1016/j.pneurobio.2008.05.004

11. Yu ML, Wei RD, Zhang T, et al. Electroacupuncture relieves pain and attenuates inflammation progression through inducing IL-10 production in CFA-induced mice. Inflammation. 2020;43(4):1233-1245. doi:10.1007/s10753-020-01203-2

12. Wang YL, Su YS, He W, Jing XH. Electroacupuncture relieved visceral and referred hindpaw hypersensitivity in colitis rats by inhibiting tyrosine hydroxylase expression in the sixth lumbar dorsal root ganglia. Neuropeptides. 2019;77:101957. doi:10.1016/j.npep.2019.101957

13. He Y, Guo X, May BH, et al. Clinical evidence for association of acupuncture and acupressure with improved cancer pain: a systematic review and meta-analysis. JAMA Oncol. 2019. doi:10.1001/ jamaoncol.2019.5233

14. Liang Y, Gu Y, Shi R, Li G, Chen Y, Huang LM. Electroacupuncture downregulates $\mathrm{P} 2 \mathrm{X} 3$ receptor expression in dorsal root ganglia of the spinal nerve-ligated rat. Mol Pain. 2019;15:1744806919847810. doi: $10.1177 / 1744806919847810$

15. Lu W, Giobbie-Hurder A, Freedman RA, et al. Acupuncture for chemotherapy-induced peripheral neuropathy in breast cancer survivors: a randomized controlled pilot trial. Oncologist. 2020;25 (4):310-318. doi:10.1634/theoncologist.2019-0489

16. Chien A, Yang CC, Chang SC, Jan YM, Yang CH, Hsieh YL. Ultrasound acupuncture for oxaliplatin-induced peripheral neuropathy in patients with colorectal cancer: a Pilot Study. PM R. 2020 doi:10.1002/pmrj.12361

17. Hsieh YL, Chou LW, Hong SF, et al. Laser acupuncture attenuates oxaliplatin-induced peripheral neuropathy in patients with gastrointestinal cancer: a pilot prospective cohort study. Acupunct Med. 2016;34(5):398-405. doi:10.1136/acupmed-2016-011112

18. Garcia MK, Cohen L, Guo Y, et al. Electroacupuncture for thalidomide/bortezomib-induced peripheral neuropathy in multiple myeloma: a feasibility study. J Hematol Oncol. 2014;7(1):41. doi:10.1186/1756-8722-7-41

19. Zhi WI, Ingram E, Li SQ, Chen P, Piulson L, Bao T. Acupuncture for bortezomib-induced peripheral neuropathy: not just for pain. Integr Cancer Ther. 2018;17(4):1079-1086. doi:10.1177/1534735418788667

20. Ben-Arye E, River Y, Keshet Y, Lavie O, Israeli P, Samuels N. Effect of a complementary/integrative medicine treatment program on taxane-induced peripheral neuropathy: a brief report. Int $J$ Gynecol Cancer. 2018;28(5):1045-1049. doi:10.1097/IGC.0000000000001246

21. Yeo JH, Yoon SY, Kwon SK, et al. Repetitive acupuncture point treatment with diluted bee venom relieves mechanical allodynia and restores intraepidermal nerve fiber loss in oxaliplatin-induced neuropathic mice. J Pain. 2016;17(3):298-309. doi:10.1016/j. jpain.2015.10.018

22. Kim W, Kim MJ, Go D, Min BI, Na HS, Kim SK. Combined effects of bee venom acupuncture and morphine on oxaliplatin-induced neuropathic pain in mice. Toxins (Basel). 2016;8(2):33. doi:10.3390/ toxins 8020033

23. Yoon SY, Lee JY, Roh DH, Oh SB. Pharmacopuncture with scolopendra subspinipes suppresses mechanical allodynia in oxaliplatin-induced neuropathic mice and potentiates clonidine-induced anti-allodynia without hypotension or motor impairment. $J$ Pain. 2018;19(10):1157-1168. doi:10.1016/j. jpain.2018.04.015

24. Zhao X, Liu L, Wang Y, Wang G, Zhao Y, Zhang Y. Electroacupuncture enhances antioxidative signal pathway and attenuates neuropathic pain induced by chemotherapeutic paclitaxel. Physiol Res. 2019;68(3):501-510. doi:10.33549/physiolres.934084
25. Lee JH, Li DX, Yoon H, et al. Serotonergic mechanism of the relieving effect of bee venom acupuncture on oxaliplatin-induced neuropathic cold allodynia in rats. BMC Complement Altern Med. 2014;14:471. doi:10.1186/1472-6882-14-471

26. Luo J, Bavencoffe A, Yang P, et al. Zinc inhibits TRPV1 to alleviate chemotherapy-induced neuropathic pain. J Neurosci. 2018;38 (2):474-483. doi:10.1523/JNEUROSCI.1816-17.2017

27. Li Y, Adamek P, Zhang H, et al. The cancer chemotherapeutic paclitaxel increases human and rodent sensory neuron responses to TRPV1 by activation of TLR4. $J$ Neurosci. 2015;35 (39):13487-13500. doi:10.1523/JNEUROSCI.1956-15.2015

28. Zhang H, Dougherty PM. Enhanced excitability of primary sensory neurons and altered gene expression of neuronal ion channels in dorsal root ganglion in paclitaxel-induced peripheral neuropathy. Anesthesiology. 2014;120(6):1463-1475. doi:10.1097/ALN.0000000000000176

29. Nieto FR, Entrena JM, Cendán CM, Pozo ED, Vela JM, Baeyens JM. Tetrodotoxin inhibits the development and expression of neuropathic pain induced by paclitaxel in mice. Pain. 2008;137(3):520-531. doi:10.1016/j.pain.2007.10.012

30. Flatters SJ, Bennett GJ. Ethosuximide reverses paclitaxel- and vincristine-induced painful peripheral neuropathy. Pain. 2004;109(1-2):150-161. doi:10.1016/j.pain.2004.01.029

31. Materazzi S, Fusi C, Benemei S, et al. TRPA1 and TRPV4 mediate paclitaxel-induced peripheral neuropathy in mice via a glutathione-sensitive mechanism. Pflugers Arch. 2012;463 (4):561-569. doi:10.1007/s00424-011-1071-x

32. Sałat K, Filipek B. Antinociceptive activity of transient receptor potential channel TRPV1, TRPA1, and TRPM8 antagonists in neurogenic and neuropathic pain models in mice. J Zhejiang Univ Sci B. 2015;16(3):167-178. doi:10.1631/jzus.B1400189

33. Hara T, Chiba T, Abe K, et al. Effect of paclitaxel on transient receptor potential vanilloid 1 in rat dorsal root ganglion. Pain. 2013;154(6):882-889. doi:10.1016/j.pain.2013.02.023

34. Chen Y, Yang C, Wang ZJ. Proteinase-activated receptor 2 sensitizes transient receptor potential vanilloid 1 , transient receptor potential vanilloid 4, and transient receptor potential ankyrin 1 in paclitaxel-induced neuropathic pain. Neuroscience. 2011;193:440-451. doi:10.1016/j.neuroscience.2011.06.085

35. Luo X, Huh Y, Bang S, et al. Macrophage toll-like receptor 9 contributes to chemotherapy-induced neuropathic pain in male mice. $J$ Neurosci. 2019;39(35):6848-6864. doi:10.1523/JNEUROSCI.3257-18.2019

36. Ochi-ishi R, Nagata K, Inoue T, Tozaki-Saitoh H, Tsuda M, Inoue K. Involvement of the chemokine CCL3 and the purinoceptor P2X7 in the spinal cord in paclitaxel-induced mechanical allodynia. Mol Pain. 2014;10:53. doi:10.1186/1744-8069-10-53

37. Andoh T, Kobayashi N, Uta D, Kuraishi Y. Prophylactic topical paeoniflorin prevents mechanical allodynia caused by paclitaxel in mice through adenosine A1 receptors. Phytomedicine. 2017;25:1-7. doi:10.1016/j.phymed.2016.12.010

38. Ma J, Kavelaars A, Dougherty PM, Heijnen CJ. Beyond symptomatic relief for chemotherapy-induced peripheral neuropathy: targeting the source. Cancer. 2018;124(11):2289-2298. doi:10.1002/cncr.31248

39. Colvin LA. Chemotherapy-induced peripheral neuropathy: where are we now? Pain. 2019;160(Suppl 1):S1-S10. doi:10.1097/j. pain.0000000000001540

40. Hu S, Huang KM, Adams EJ, Loprinzi CL, Lustberg MB. Recent developments of novel pharmacologic therapeutics for prevention of chemotherapy-induced peripheral neuropathy. Clin Cancer Res. 2019;25(21):6295-6301. doi:10.1158/1078-0432.CCR-18-2152

41. Areti A, Yerra VG, Naidu V, Kumar A. Oxidative stress and nerve damage: role in chemotherapy induced peripheral neuropathy. Redox Biol. 2014;2:289-295. doi:10.1016/j.redox.2014.01.006

42. Melli G, Taiana M, Camozzi F, et al. Alpha-lipoic acid prevents mitochondrial damage and neurotoxicity in experimental chemotherapy neuropathy. Exp Neurol. 2008;214(2):276-284. doi:10.1016/j. expneurol.2008.08.013 
43. Flatters SJ, Bennett GJ. Studies of peripheral sensory nerves in paclitaxel-induced painful peripheral neuropathy: evidence for mitochondrial dysfunction. Pain. 2006;122(3):245-257. doi:10.1016/j. pain.2006.01.037

44. Zheng H, Xiao WH, Bennett GJ. Functional deficits in peripheral nerve mitochondria in rats with paclitaxel- and oxaliplatin-evoked painful peripheral neuropathy. Exp Neurol. 2011;232(2):154-161. doi:10.1016/j.expneurol.2011.08.016

45. Galley HF, McCormick B, Wilson KL, Lowes DA, Colvin L, Torsney C. Melatonin limits paclitaxel-induced mitochondrial dysfunction in vitro and protects against paclitaxel-induced neuropathic pain in the rat. $J$ Pineal Res. 2017;63(4):4. doi:10.1111/jpi.12444

46. Gornstein E, Schwarz TL. The paradox of paclitaxel neurotoxicity: mechanisms and unanswered questions. Neuropharmacology. 2014;76(Pt A):175-183. doi:10.1016/j.neuropharm.2013.08.016

47. Liu CC, Lu N, Cui Y, et al. Prevention of paclitaxel-induced allodynia by minocycline: effect on loss of peripheral nerve fibers and infiltration of macrophages in rats. Mol Pain. 2010;6:76. doi:10.1186/1744-8069-6-76

48. Shemesh OA, Spira ME. Paclitaxel induces axonal microtubules polar reconfiguration and impaired organelle transport: implications for the pathogenesis of paclitaxel-induced polyneuropathy. Acta Neuropathol. 2010;119(2):235-248. doi:10.1007/s00401-009-0586-0

49. Sahenk Z, Barohn R, New P, Mendell JR. Taxol neuropathy. Electrodiagnostic and sural nerve biopsy findings. Arch Neurol. 1994;51(7):726-729. doi:10.1001/archneur.1994.00540190110024

50. Jia M, Wu C, Gao F, et al. Activation of NLRP3 inflammasome in peripheral nerve contributes to paclitaxel-induced neuropathic pain. Mol Pain. 2017;13:1744806917719804. doi:10.1177/1744806917719804

51. Siau C, Xiao W, Bennett GJ. Paclitaxel- and vincristine-evoked painful peripheral neuropathies: loss of epidermal innervation and activation of langerhans cells. Exp Neurol. 2006;201(2):507-514. doi:10.1016/j.expneurol.2006.05.007

52. Wu J, Hocevar M, Bie B, Foss JF, Naguib M. Cannabinoid type 2 receptor system modulates paclitaxel-induced microglial dysregulation and central sensitization in rats. J Pain. 2019;20(5):501-514. doi:10.1016/j.jpain.2018.10.007

53. Burgos E, Gómez-Nicola D, Pascual D, Martín MI, Nieto-Sampedro M, Goicoechea C. Cannabinoid agonist WIN 55,212-2 prevents the development of paclitaxel-induced peripheral neuropathy in rats. Possible involvement of spinal glial cells. Eur $J$ Pharmacol. 2012;682(1-3):62-72. doi:10.1016/j.ejphar.2012.02.008

54. Yan X, Li F, Maixner DW, et al. Interleukin-1beta released by microglia initiates the enhanced glutamatergic activity in the spinal dorsal horn during paclitaxel-associated acute pain syndrome. Glia. 2019;67(3):482-497. doi:10.1002/glia.23557

55. Li Y, Zhang H, Kosturakis AK, et al. MAPK signaling downstream to TLR4 contributes to paclitaxel-induced peripheral neuropathy. Brain Behav Immun. 2015;49:255-266. doi:10.1016/j.bbi.2015.06.003

56. Li Y, Tatsui CE, Rhines LD, et al. Dorsal root ganglion neurons become hyperexcitable and increase expression of voltage-gated T-type calcium channels (Cav3.2) in paclitaxel-induced peripheral neuropathy. Pain. 2017;158(3):417-429. doi:10.1097/j. pain.0000000000000774

57. Li Y, Zhang H, Zhang H, Kosturakis AK, Jawad AB, Dougherty PM. Toll-like receptor 4 signaling contributes to paclitaxel-induced peripheral neuropathy. J Pain. 2014;15(7):712-725. doi:10.1016/j. jpain.2014.04.001

58. Zeng QZ, Yang F, Li CG, et al. Paclitaxel enhances the innate immunity by promoting NLRP3 inflammasome activation in macrophages. Front Immunol. 2019;10:72. doi:10.3389/ fimmu.2019.00072

59. Son S, Shim DW, Hwang I, Park JH, Yu JW. Chemotherapeutic agent paclitaxel mediates priming of NLRP3 inflammasome activation. Front Immunol. 2019;10:1108. doi:10.3389/fimmu.2019.01108
60. Broz P, Dixit VM. Inflammasomes: mechanism of assembly, regulation and signalling. Nat Rev Immunol. 2016;16(7):407-420. doi:10.1038/nri.2016.58

61. Ferris CF, Nodine S, Pottala T, et al. Alterations in brain neurocircuitry following treatment with the chemotherapeutic agent paclitaxel in rats. Neurobiol Pain. 2019;6:100034. doi:10.1016/j.ynpai.2019.100034

62. Masocha W. Comprehensive analysis of the GABAergic system gene expression profile in the anterior cingulate cortex of mice with paclitaxel-induced neuropathic pain. Gene Expr. 2015;16 (3):145-153. doi:10.3727/105221615X14181438356337

63. Masocha W, Parvathy SS. Preventative and therapeutic effects of a GABA transporter 1 inhibitor administered systemically in a mouse model of paclitaxel-induced neuropathic pain. PeerJ. 2016;4:e2798. doi:10.7717/peerj.2798

64. Xu H, Wu LJ, Wang H, et al. Presynaptic and postsynaptic amplifications of neuropathic pain in the anterior cingulate cortex. $J$ Neurosci. 2008;28(29):7445-7453. doi:10.1523/JNEUROSCI.1812-08.2008

65. Yadav R, Yan X, Maixner DW, Gao M, Weng HR. Blocking the GABA transporter GAT-1 ameliorates spinal GABAergic disinhibition and neuropathic pain induced by paclitaxel. J Neurochem. 2015;133(6):857-869. doi:10.1111/jnc. 13103

66. Alkislar I, Miller AR, Hohmann AG, et al. Inhaled cannabis suppresses chemotherapy-induced neuropathic nociception by decoupling the raphe nucleus: a Functional Imaging Study in rats. Biol Psychiatry. 2020; S2451-9022(20)30370-0. doi:10.1016/j.bpsc.2020.11.015

67. Chen JDZ, Ni M, Yin J. Electroacupuncture treatments for gut motility disorders. Neurogastroenterol Motil. 2018;30(7):e13393. doi:10.1111/nmo. 13393

68. Chang S, Kwon OS, Bang SK, et al. Peripheral sensory nerve tissue but not connective tissue is involved in the action of acupuncture. Front Neurosci. 2019;13:110. doi:10.3389/fnins.2019.00110

69. Ulloa L, Quiroz-Gonzalez S, Torres-Rosas R. Nerve stimulation: immunomodulation and control of inflammation. Trends Mol Med. 2017;23(12):1103-1120. doi:10.1016/j.molmed.2017.10.006

70. Lv Q, Wu F, Gan X, et al. The involvement of descending pain inhibitory system in electroacupuncture-induced analgesia. Front Integr Neurosci. 2019;13:38. doi:10.3389/fnint.2019.00038

71. Donald GK, Tobin I, Stringer J. Evaluation of acupuncture in the management of chemotherapy-induced peripheral neuropathy. Acupunct Med. 2011;29(3):230-233. doi:10.1136/acupmed.2011.010025

72. Schroeder S, Meyer-Hamme G, Epplée S. Acupuncture for chemotherapy-induced peripheral neuropathy (CIPN): a pilot study using neurography. Acupunct Med. 2012;30(1):4-7. doi:10.1136/ acupmed-2011-010034

73. Lu W, Matulonis UA, Dunn JE, et al. The feasibility and effects of acupuncture on quality of life scores during chemotherapy in ovarian cancer: results from a pilot, randomized sham-controlled trial. Med Acupunct. 2012;24(4):233-240. doi:10.1089/acu.2012.0904

74. Greenlee H, Crew KD, Capodice J, et al. Randomized sham-controlled pilot trial of weekly electro-acupuncture for the prevention of taxane-induced peripheral neuropathy in women with early stage breast cancer. Breast Cancer Res Treat. 2016;156 (3):453-464. doi:10.1007/s10549-016-3759-2

75. Ben-Horin I, Kahan P, Ryvo L, Inbar M, Lev-Ari S, Geva R. Acupuncture and reflexology for chemotherapy-induced peripheral neuropathy in breast cancer. Integr Cancer Ther. 2017;16 (3):258-262. doi:10.1177/1534735417690254

76. Bao T, Seidman AD, Piulson L, et al. A phase IIA trial of acupuncture to reduce chemotherapy-induced peripheral neuropathy severity during neoadjuvant or adjuvant weekly paclitaxel chemotherapy in breast cancer patients. Eur J Cancer. 2018;101:12-19. doi:10.1016/j. ejca.2018.06.008

77. Jeong YJ, Kwak MA, Seo JC, et al. Acupuncture for the treatment of taxane-induced peripheral neuropathy in breast cancer patients: a pilot trial. Evid Based Complement Alternat Med. 2018;2018:5367014. doi:10.1155/2018/5367014 
78. Molassiotis A, Suen LKP, Cheng HL, et al. A randomized assessor-blinded wait-list-controlled trial to assess the effectiveness of acupuncture in the management of chemotherapy-induced peripheral neuropathy. Integr Cancer Ther. 2019;18:1534735419836501. doi:10.1177/1534735419836501

79. Meng X, Zhang Y, Li A, et al. The effects of opioid receptor antagonists on electroacupuncture-produced anti-allodynia/hyperalgesia in rats with paclitaxel-evoked peripheral neuropathy. Brain Res. 2011;1414:58-65. doi:10.1016/j.brainres.2011.08.004

80. Han JS. Acupuncture: neuropeptide release produced by electrical stimulation of different frequencies. Trends Neurosci. 2003;26 (1):17-22. doi:10.1016/s0166-2236(02)00006-1

81. Choi JW, Kang SY, Choi JG, et al. Analgesic effect of electroacupuncture on paclitaxel-induced neuropathic pain via spinal opioidergic and adrenergic mechanisms in mice. Am J Chin Med. 2015;43 (1):57-70. doi:10.1142/S0192415X15500044

82. Choi J, Jeon C, Lee JH, et al. Suppressive effects of bee venom acupuncture on paclitaxel-induced neuropathic pain in rats: mediation by spinal $\alpha_{2}$-adrenergic receptor. Toxins (Basel). 2017;9(11):E351. doi:10.3390/toxins9110351

83. Kim MJ, Lee JH, Jang JU, Quan FS, Kim SK, Kim W. The efficacy of combination treatment of gabapentin and electro-acupuncture on paclitaxel-induced neuropathic pain. Korean J Physiol Pharmacol. 2017;21(6):657-666. doi:10.4196/kjpp.2017.21.6.657

84. Zhang Y, Li A, Xin J, et al. Electroacupuncture alleviates chemotherapy-induced pain through inhibiting phosphorylation of spinal CaMKII in rats. Eur J Pain. 2018;22(4):679-690. doi:10.1002/ejp.1132
85. Zhang H, Xiang HC, Jia M, et al. Mechanism on the involvement of CB2 receptor in inhibiting the activation of NLRP3 inflammasome by electroacupuncture on alleviating neuropathic pain after paclitaxel chemotherapy. CJTCMP. 2018;33(5):2103-2107.

86. Li Y, Yin C, Li $\mathrm{X}$, et al. Electroacupuncture alleviates paclitaxel-induced peripheral neuropathic pain in rats via suppressing TLR4 signaling and TRPV1 upregulation in sensory neurons. Int J Mol Sci. 2019;20(23):E5917. doi:10.3390/ijms20235917

87. Zhao YX, Yao MJ, Liu Q, Xin JJ, Gao JH, Yu XC. Electroacupuncture treatment attenuates paclitaxel-induced neuro-

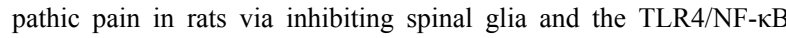
pathway. J Pain Res. 2020;13:239-250. doi:10.2147/JPR.S241101

88. Lin D, De La Pena I, Lin L, Zhou SF, Borlongan CV, Cao C. The neuroprotective role of acupuncture and activation of the BDNF signaling pathway. Int $J$ Mol Sci. 2014;15(2):3234-3252. doi:10.3390/ijms 15023234

89. Liang J, Lu J, Cui SF, Wang JR, Tu Y. [Effect of acupuncture on expression of brain-derived neurotrophic factor gene and protein in frontal cortex and hippocampus of depression rats]. Zhen Ci Yan Jiu. 2012;37(1):20-24. Chinese.

90. Tao J, Zheng Y, Liu W, et al. Electro-acupuncture at LI11 and ST36 acupoints exerts neuroprotective effects via reactive astrocyte proliferation after ischemia and reperfusion injury in rats. Brain Res Bull. 2016;120:14-24. doi:10.1016/j.brainresbull.2015.10.011
Journal of Pain Research

\section{Publish your work in this journal}

The Journal of Pain Research is an international, peer reviewed, open access, online journal that welcomes laboratory and clinical findings in the fields of pain research and the prevention and management of pain. Original research, reviews, symposium reports, hypothesis formation and commentaries are all considered for publication. The manuscript management system is completely online and includes a very quick and fair peer-review system, which is all easy to use. Visit http:// www.dovepress.com/testimonials.php to read real quotes from published authors. 